\title{
An Unusual Soft Tissue Tumor
}

BHARATH MANU AKKARA VEETIL, MBBS; TIM BONGARTZ, MD, Division of Rheumatology, Mayo Clinic, 200 First Street SW, Rochester, Minnesota 55905, USA. Address correspondence to Dr. Akkara Veetil; E-mail: AkkaraVeetil.BharathManu@mayo.edu. J Rheumatol 2010;37:1269-70; doi: $10.3899 /$ jrheum.091338

Tophaceous uric acid deposits are an important differential diagnosis when evaluating benign soft tissue masses, even in the absence of a history of inflammatory arthritis ${ }^{1,2}$.

A 63-year-old man presented with a slow-growing tumor on the plantar aspect of the right forefoot (Figure 1). The mass was firm, painless, and sessile. There was no history of trauma or previous arthritis. Computed tomography (CT) of the right foot was performed on a dual-source CT scanner at
$140 \mathrm{kVp}$ and $80 \mathrm{kVp}$ tube potential. Postprocessing spectral analysis for radiograph attenuation characteristic of uric acid was performed, identifying the tumor as a large tophaceous uric acid deposit ${ }^{3,4}$ (Figure 2). Uric acid is also seen in several areas of the entire right foot including the plantar fascia, Achilles tendon, anterior tibial tendon, and several joint areas. Aspiration of the first metatarsophalangeal joint confirmed the presence of negatively birefringent crystals.
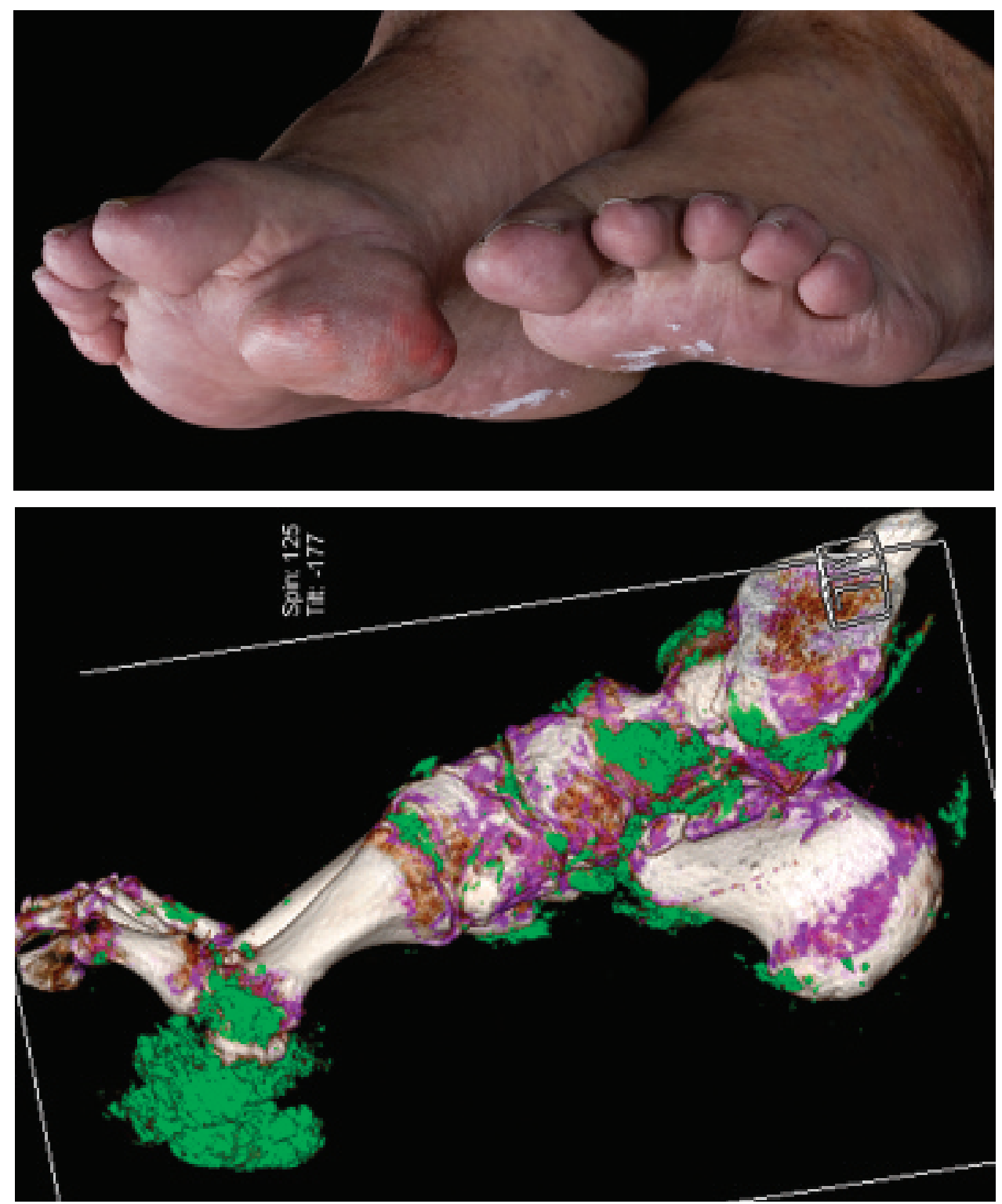

Figure 1. Slow-growing tumor on the right forefoot. 


\section{REFERENCES}

1. Artmann A, Ratzenbock M, Noszian I, Trieb K. Dual energy CT a new perspective in the diagnosis of gout. Rofo 2009 Oct 27. [Epub ahead of print]

2. Choi HK, Al-Arfaj AM, Eftekhari A, Munk PL, Shojania K, Reid $\mathrm{G}$, et al. Dual energy computed tomography in tophaceous gout. Ann Rheum Dis 2009;68:1609-12.

3. Ferrandino MN, Pierre SA, Simmons WN, Paulson EK, Albala
DM, Preminger GM. Dual-energy computed tomography with advanced postimage acquisition data processing: improved determination of urinary stone composition. J Endourol 2010 Jan 27. [Epub ahead of print]

4. Primak AN, Fletcher JG, Vrtiska TJ, Dzyubak OP, Lieske JC, Jackson ME, et al. Noninvasive differentiation of uric acid versus non-uric acid kidney stones using dual-energy CT. Acad Radiol 2007;14:1441-7. 